\title{
ARTICLE
}

https://doi.org/10.1057/s41599-018-0212-7

\section{Future scenarios of global plastic waste generation and disposal}

\author{
Laurent Lebreton ${ }^{1,2} \&$ Anthony Andrady ${ }^{3}$
}

\begin{abstract}
The accumulation of mismanaged plastic waste (MPW) in the environment is a global growing concern. Knowing with precision where litter is generated is important to target priority areas for the implementation of mitigation policies. In this study, using countrylevel data on waste management combined with high-resolution distributions and long-term projections of population and the gross domestic product (GDP), we present projections of global MPW generation at $\sim 1 \mathrm{~km}$ resolution from now to 2060. We estimated between 60 and 99 million metric tonnes (Mt) of MPW were produced globally in 2015. In a business-as-

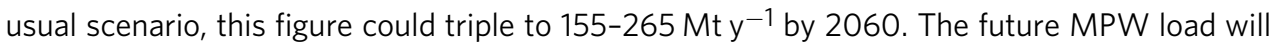
continue to be disproportionately high in African and Asian continents even in the future years. However, we show that this growth in plastic waste can be reduced if developing economies significantly invest in waste management infrastructures as their GDP grows in the future and if efforts are made internationally to reduce the fraction of plastic in municipal solid waste. Using our projections, we also demonstrate that the majority of MPW (91\%) are transported via watersheds larger than $100 \mathrm{~km}^{2}$ suggesting that rivers are major pathways for plastic litter to the ocean.
\end{abstract}

\footnotetext{
${ }^{1}$ The Ocean Cleanup Foundation, Rotterdam, The Netherlands. ${ }^{2}$ The Modelling House, Raglan, New Zealand. ${ }^{3}$ North Carolina State University, Raleigh, NC, USA. Correspondence and requests for materials should be addressed to L.L. (email: laurent.lebreton@theoceancleanup.com)
} 


\section{Introduction}

ommercial production of plastics that started around 1950's has enjoyed exceptional growth, to reach the present global annual production of 330 million metric tonnes (Mt) for 2016 (Plastics Europe, 2017). Including the resin used in spinning textile fibres (Lenzing Group, 2016), this figure is closer to $393 \mathrm{Mt}$, a value that interestingly matches the global human biomass. At the present rate of growth, plastics production is estimated to double within the next 20 years. This impressive success of plastics is unparalleled by any competing materials used in packaging or construction, the two major applications areas of plastics. Plastics production is energy intensive with resins having an embodied energy of $62-108 \mathrm{MJ} \mathrm{kg}^{-1}$ (inclusive of feedstock energy) much higher than for paper, wood, glass or metals (except for Aluminium) (Hammond and Jones, 2008). About $4 \%$ of fossil-fuel extracted annually is presently used as raw materials for plastics (British Plastics Federation, 2008) and it is the natural gas liquid fraction or low-value gaseous fraction from petroleum refining that is mostly used to make plastics. The demand on fossil fuel, energy, as well as the associated carbon emissions by the industry, will increase as the future consumer demand for plastics increases. By year 2050 plastics manufacturing and processing may account for as much as $20 \%$ of petroleum consumed globally and $15 \%$ of the annual carbon emissions budget (World Economic Forum, 2016). There is considerable interest in switching to biomass feedstock to make bioplastics that include the most-used synthetic plastic, polyethylene.

It is the considerable societal benefits of plastics (Andrady and Neal, 2009) that account for its popularity as a material. Plastics represent a low-cost, easily formable, high-modulus, hydrophobic, bio-inert material that finds use in a bewildering range of consumer products. It is often the preferred, and with some products an indispensable, choice in consumer packaging that accounts for $42 \%$ of the global annual resin production (Geyer et al., 2017). Transparent packaging films that are both strong and impermeable to gases and moisture, facilitate conformal packaging (vacuum packs) or controlled-environment packaging (as in red-meat packs). The exceptional thermal insulation of expanded polystyrene foam has ensured its lead in hot-food service applications (Andrady and Neal, 2009). The handful of resins that dominate packaging and food service applications are also the most frequently found in municipal solid waste as well as in marine debris (Andrady, 2011): these are polyethylene, polypropylene, polyethylene terephthalate, and polystyrene. Generally, the lighter, more durable and less expensive plastics (especially polyvinyl chloride) have replaced metal and even wood in building applications that accounts for about $20 \%$ of global production (Plastics Europe, 2017). The same is true for comfort fibres in fabric and in carpeting where plastic has replaced natural fibres such as wool, cotton or silk, for the most part. Plastic products are indispensable in medical applications that require sterility and microbial inertness.

Projected increase in future plastic use will result in a concomitant increase in post-consumer plastic waste. For instance, by 2025 the global urban population is estimated to generate > $6 \mathrm{Mt}$ of solid waste daily (Hoornweg et al. 2013). Even using the present fraction of $\sim 10 \%$ plastics in the solid waste stream, this amounts to over $200 \mathrm{Mt}$ of waste plastics: this was the entire global plastic resin production in 2002 (Plastics Europe, 2014). The discouragingly slow growth in recycling rates and the likely increase in single-use products, both exacerbate this situation. Packaging products are almost always discarded with their functional characteristics virtually intact, permitting both facile re-use and recycling, however only about $9.4 \%$ of plastics (E.P.A., 2016) is presently recycled in the US mainly due to collection costs, lack of requisite infrastructure and poor demand by processors for recycled plastic granulate.

Adding to risks of local flooding by clogging drains and degradation of air quality from open dumps, a serious concern is where mismanaged waste located near inland waterways or in coastal regions serves as an input of plastics into rivers and the oceans. Microplastics or small fragments $(<5 \mathrm{~mm}$ in size), mostly derived by surface weathering degradation of plastic debris (Andrady, 2017), now ubiquitous in soil (Rillig, 2012), rivers and lakes (Lebreton et al., 2017) as well as in the oceans (Barnes et al., 2009). Virgin pellets and some manufactured products such as microbeads, also find their way into oceans (Mason et al., 2016). The smaller the dimension of the microplastic, the wider will be the range of marine organisms that are able to ingest or otherwise interact with them. Microplastics absorb and concentrate hydrophobic pollutants present in sea water at very low concentrations and these can be bioavailable to the ingesting species. Over 660 species (Secretariat of the Convention on Biological Diversity, 2012), ranging from seabirds, fish, bivalves to the zooplanktons at the bottom of the marine food chain, are known to be affected by plastic debris (Ivar do Sul and Costa, 2014; Van Cauwenberghe and Janssen, 2014) and there is credible evidence of the bioavailability of pollutants concentrated in the plastic (Heskett et al., 2012; Chen et al., 2017) to the ingesting organisms. Potential trophic transfer of the plastics and pollutants along the food chain (Au et al., 2017) and their potential tainting of human seafood (Santillo et al., 2017) are particularly serious concerns.

However, broad estimates of global plastic production or MPW generation are inadequate to assess the regional impacts of plastic waste on the ecosystem that would dictate the need for mitigation. Future increase in population density and therefore regional or even country-level plastic waste generation are spatially heterogeneous. For instance, while the global population is predicted to increase to over 9.5 billion in 2025 over $97 \%$ of this growth will be in Asia and Africa (United Nations, 2015). Coastal communities in those regions will place a disproportionate plastic waste burden on the environment and especially the ocean. Understanding this spatial variation in plastics influx into the ocean requires the development of a high-resolution map of global plastic usage that would indicate geographic bias in future plastic waste trends.

Generally, plastics in the global ecosystem is distributed between three fractions: plastics in use, post-consumer managed plastic waste, and a mismanaged plastic waste (MPW) fraction, the last of which includes urban litter (Geyer et al., 2017). Packaging-related plastics have a particularly short in-use phase and therefore dominate municipal plastic waste and subsequently the mismanaged waste as well. In addition to urban litter, mismanaged waste also includes inadequately contained waste such as open dumps and are therefore transportable via runoff and wind. Some mismanaged waste may be collected by street sweepers and concerned citizen groups and be re-introduced in one of the two first categories. Managed waste is accounted for and is typically disposed of by incineration or landfilling. Both per capita use of plastics and the population density at a given location determines the local plastic demand by consumers, reflected in the in-use fraction. The former generally scales with the local gross domestic product (GDP) (Hoornweg et al., 2013) with the more affluent countries using as much as over $100 \mathrm{~kg} / \mathrm{pp} /$ year (Waste Atlas, 2016). But in populous countries such as India or China a relatively low per capita use of plastics coupled with a high population density can still yield large tonnage of plastic waste. A recent study (Jambeck et al., 2015) based on a World Bank dataset (Hoornweg and Bhada-Tata, 2012) on countryspecific waste generation and management concluded that the 
fraction of this waste that is reaching the oceans represented 4.8 to $12.7 \mathrm{Mt}$ of plastics in 2010 from populations living within $50 \mathrm{~km}$ from the coastline.

The present effort is aimed at examining the possibility of improving the granularity of country-level plastic waste generation data, using reasonable assumptions based on population density and affluence. A comprehensive dataset of municipality-level waste generation data for different countries is not presently available. While we appreciate the limitations of evolving countrylevel waste generation data into higher-resolution maps of finer granularity, we believe the exercise is important as it yields likely global 'hot spots' for plastic waste at present and progressed into the near future. An important trend is the increased migration into urban areas that in general would tend to exacerbate the developing hot-spots. We therefore employ high-resolution $(30 \times$ 30 arc seconds) population density and GDP distributions to model waste data at cells in a finer geographic grid. The use of these two indicators allows to represent plastic waste generation near large urban areas but also to possibly predict the likely accumulation near major transportation axes such as roads and railways which may not be represented by municipality-level data.

\section{Methods}

Consumer demand for plastics and per capita GDP relation. We use data distributed by Waste Atlas (2016) for per capita municipal solid waste generation (expressed in $\mathrm{kg} \mathrm{y}^{-1}$ ), mismanaged fraction (expressed in \%) and plastic fraction in

\begin{tabular}{|c|c|c|c|}
\hline Per capita GDP (2016 USD) & $r$ & $p$ & $n$ \\
\hline $\begin{array}{l}\text { Per capita municipal solid } \\
\text { waste generation }\left(\mathrm{kg} \mathrm{y}^{-1}\right)\end{array}$ & 0.67 & $<0.005$ & 160 \\
\hline $\begin{array}{l}\text { Unsound disposal fraction } \\
(\%)\end{array}$ & -0.62 & $<0.005$ & 95 \\
\hline $\begin{array}{l}\text { Plastic fraction in municipal } \\
\text { solid waste }(\%)\end{array}$ & 0.14 & 0.17 & 105 \\
\hline
\end{tabular}

Information on per capita municipal solid waste generation rate, unsound disposal fraction and plastic fraction in municipal solid waste. Pair with $p$ values below 0.005 (in bold) are statistically significant. Per capita GDP demonstrates a statistically significant correlation with per capita solid municipal waste generation and unsound disposal fraction, respectively positive and negative.

A

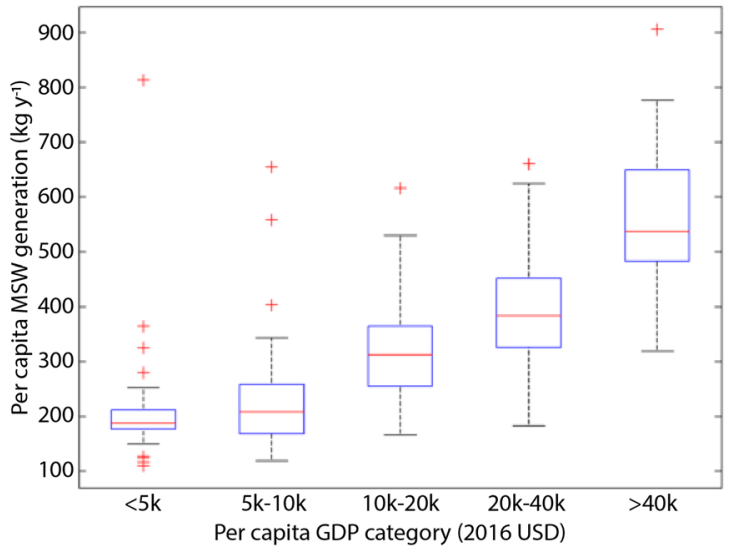

municipal solid waste (expressed in \%). Hitherto, models of plastic waste generation had relied on the data set compiled by the World Bank (Hoornweg and Bhada-Tata, 2012). In this effort we use an alternative source, the Waste Atlas, a resource compiled using country-level data submitted by individual experts from each country. More recent and detailed data are available from this source compared to the World Bank dataset. A comparison between the two datasets is provided in Supplementary Figure 1. Unfortunately, this collection is non-exhaustive, and information is provided for some countries only. Data is available for $n=160$ countries for per capita municipal solid waste generation, $n=95$ countries for unsound disposal fraction and $n=105$ countries for plastic proportion in municipal solid waste.

When data was available, we compared these variables with per capita GDP provided by the International Monetary Fund (IMF, 2016). We performed a Pearson product-moment correlation test for the three waste variables against per capita GDP (Table 1). Both per capita municipal solid waste generation and mismanaged fraction showed a statistically significant correlation with per capita GDP. The correlation was expectedly positive for waste generation reflecting the higher consumption levels in rich country and negative for the mismanaged fraction showing a greater amount of waste unsoundly disposed for developing countries (Fig. 1). However, per capita GDP and the proportion of plastic in municipal solid waste did not demonstrate a statistically significant relationship. This suggests that the proportion of plastic in solid waste is generally independent of the per capita GDP of a country. The proportion of plastic in municipal solid waste for countries provided by Waste-Atlas was homogeneously distributed when compared against per capita GDP with an average value of $10.9 \%$ and standard deviation of $4.5 \%(n=105)$.

The statistically significant correlations between per capita municipal solid waste generation, mismanaged fraction and per capita GDP allow us to predict these quantities when they are not reported by Waste Atlas ( $n=160$ countries reported). When the proportion of plastic in municipal solid waste is not reported we used the global reported average.

Model formulation. Current per capita plastic waste generation is calculated by multiplying per capita municipal solid waste generation by the fraction of plastic found within waste. When waste generation data for a country was missing, we derived per capita municipal solid waste generation $\left(M s_{c}\right)$ from per capita

B

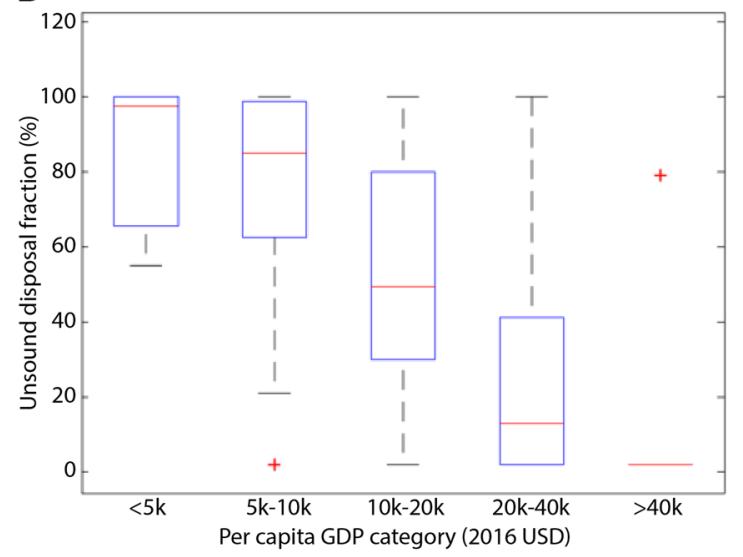

Fig. 1 Per capita municipal solid waste (MSW) generation a and mismanaged fraction $\mathbf{b}$ for different per capita GDP categories of country. Red line shows the median, the blue box extends from the 25th to 75th percentile, the black whisker extends from minimum and maximum non-outliers and red crosses shows outliers 
GDP ( $X_{c}$, in 2016 USD) by introducing an empirical function:

$$
M s_{c}=a X_{c}^{b}
$$

Where $a=11.434$ (lower: 11.218 , upper: 11.953 ) and $b=0.3433$ (lower: 0.3565, upper: 0.3298), best fit parameters for $n=160$ countries (Supplementary Figure 2a). The production rates reported by Waste Atlas completed with estimations from this relation allowed us to draw an exhaustive list of per capita municipal solid waste generation at national level, worldwide. For any country, an estimate of total plastic waste produced $(A)$ could then be formulated:

$$
A=p * M s_{c} * Y
$$

Where $p$ is the average proportion of plastic in solid waste and $Y$ is the country's total population. When $p$ was not reported by Waste Atlas, we used the global average of $10.9 \pm 0.85 \%$ ( $95 \%$ C.I., $n=105)$. Value of $p$ is assumed to be the same for all unmanaged waste including litter. This method for estimating global plastic waste generation has a drawback, however, in that it does not account for spatial heterogeneity within a country. Furthermore, when integrating national plastic waste generation at global scale, the total was estimated to range between 212 and $229 \mathrm{Mt} \mathrm{y}^{-1}$ for 2015. A figure higher than the predicted amount derived from production data, assuming conservatively that $50 \%$ of plastic production goes to packaging and household items (i.e., $~ 50 \%$ of $380 \mathrm{Mt}$ in 2015 is $190 \mathrm{Mt}$ ). A similar overestimation was found using the World Bank dataset with which the same method resulted in $212 \mathrm{Mt}$ of global plastic waste for 2015. We explain these results by a bias in estimating solid waste generation in rural areas. Waste management data is mainly reported for urban centres and we trust that levels of per capita use may not be representative of rural areas.

An important model assumption here, is that per capita solid waste generation scales with GDP inside a country. We used high resolution ( 30 by 30 arc seconds, $\sim 1 \mathrm{~km}$ ) gridded population density data (Landscan, 2014) and sub-national GDP data (UNEP/DEWA/GRID-Geneva, 2012). The global GDP dataset distinguishes between rural and urban population and allows the mapping of per capita GDP at sub-national scale. We combined these two datasets to estimate per capita solid waste generation derived from computed per capita GDP. For a model grid cell $i$, inside a given country, we computed the plastic waste generation:

$$
A(i)=p *\left(M s_{c}+a *\left(\left(\frac{x(i)}{y(i)}\right)^{b}-X_{c}^{b}\right)\right) * y(i)
$$

Where $x(i)$ is GDP and $y(i)$ is population in cell $i$. The additional correction term allows to scale generation between urban and rural zones. If per capita GDP in cell $i$ is lower than the national average $X_{c}$, the per capita waste generation, term is reduced from the national value. We computed national and global generation by integrating over land cells. Our global estimated municipal plastic waste generation of $181 \mathrm{Mt}$ for 2015 is closer to predictions from production data and confirms our assumptions.

For future projections we used country-scale population projections distributed by the United Nations (2015) from 2015 to 2060. We sourced national GDP projections for 2015 to 2021 from the IMF (2016) and long-term growth rate projections for 2022 to 2060 from the Organisation for Economic Cooperation and Development (OECD, 2014). Since the gridded distribution of population and GDP used in this study are representative of the current situation, we scaled the distribution in time using the country scale projections. As such we neglected the possible migration of population or variations in domestic product inside countries for our future projections as we considered the relative distribution to remain the same over time. For time $t$ and in model cell $i$ of a given country, we computed the plastic waste generation $A(i, t)$ following:

$$
\begin{gathered}
A(i, t)= \\
p *\left(M s_{c}\left(t_{0}\right)+a *\left(\frac{x(i) \sum_{i}^{c} y(i)}{y(i) \sum_{i}^{c} x(i)} * X_{c}(t)\right)^{b}-a * X_{c}\left(t_{0}\right)^{b}\right) \\
* \frac{y(i)}{\sum_{i} y(i)} * Y(t)
\end{gathered}
$$

Where $M s_{c}\left(t_{0}\right)$ and $X_{c}\left(t_{0}\right)$ are the current national value for respectively per capita solid waste generation and per capita GDP. $x(i)$ and $y(i)$ are the current GDP and population in cell $i . X c(t)$ and $Y(t)$ are the respective national projections of per capita GDP and population at time $t$. This model allowed us to produce high resolution maps of future plastic waste generation from 2015 to 2060, every five years. An additional map was created for 2010 to compare results with previous estimates (Supplementary Figure 3).

Municipal waste management scenarios. We derived mismanaged plastic waste generation from fraction of unsound disposal per country reported by Hoornweg and Bhada-Tata (2012) as proposed in a previous assessment (Jambeck et al. 2015). When data was not reported (50\% of countries) we proposed an empirical formulation to estimate the fraction of mismanaged waste $K$ from per capita GDP ( $X_{c}$ in 2016 USD) based on the correlation introduced earlier:

$$
K=e X_{c}+f
$$

With $e=-3.1310^{-3}$ and $f=104$ (lower: 70, upper: 138), best fit parameters for $n=95$ countries (Supplementary Figure 2b). Many countries with a high GDP per capita had a reported mismanaged fraction of $0 \%$. To account for accidental and deliberate littering in these countries, Jambeck et al. (2015) used a minimum threshold of $2 \%$ of mismanaged waste. In this study, we conservatively considered a minimum of $1 \%$ for our midpoint estimates. However, as a significant degree of uncertainty is associated with this value, we considered using an upper and lower threshold by varying orders of magnitude from 0.1 to $10 \%$ minimum mismanaged waste. As some countries reported $100 \%$ of mismanaged waste, we also applied a threshold on the upper limit to account for opportunistic recycling and waste picking. The upper threshold for mismanaged waste was respectively set to 90, 99 and 99.9\% for lower, mid and upper estimates.

Reported and estimated mismanaged fractions $K$ were associated to plastic waste generation per country $A$ to produce quantities of MPW B:

$$
B=K * A
$$

For future projections, we assumed three scenarios. For scenario A, we considered the case of business-as-usual where the mismanaged fraction reported by Waste Atlas (2016) were maintained into the future years (estimated from equation (5) at 2015 levels when not reported). In scenario B, we varied the mismanaged fraction $K(t)$ for each country over time from an initial value $K\left(t_{0}\right)$ using the following:

$$
K(t)=K\left(t_{o}\right)+e *\left(X_{c}(t)-X_{c}\left(t_{0}\right)\right)
$$

Since $e$ is negative, a growth in per capita GDP $(X c)$ from $t_{0}$ to $t$ results in the decrease of mismanaged fraction (i.e., as the economy grows, waste management infrastructure improves). A 


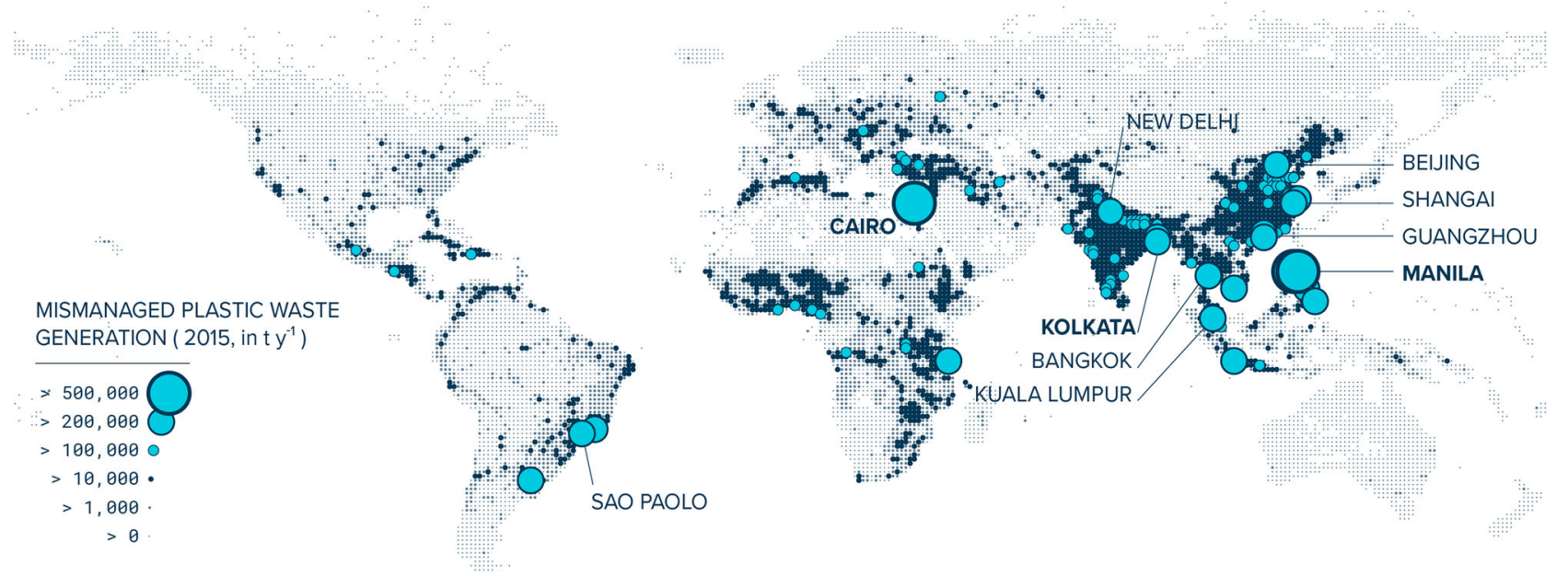

Fig. 2 Global mismanaged plastic waste (MPW) generation in 2015. Plastic waste generation is computed globally on a 30 by 30 arc seconds resolution reflecting geographical heterogeneity based on population and GDP distributions. National data on waste management reported per countries (Waste Atlas, 2016) is derived to estimate the mismanaged fraction at local scale. The 10 largest producing urban centres are labelled on the map with Manila, Cairo and Kolkata as the leading agglomerations

minimum threshold ranging from 0.1 to $10 \%$ and maximum from 90 to $99.9 \%$ were also applied to this relation. Finally, in scenario $\mathrm{C}$, we used the same assumption as in scenario $\mathrm{B}$ and further reduced the input of individual countries by capping the fraction $p$ of plastic in solid waste to $10 \%$ by 2020 and to $5 \%$ by 2040 .

Plastic waste and watersheds. We introduced a spatial indicator representing the size of the watershed of which a model cell belongs to. Starting from the HydroSHEDS database (Lehner et al., 2008) regrouping global watershed boundaries as polygonal features, we computed the area covered by individual watersheds and created a 30 arc second resolution global grid to match with our plastic waste generation maps. Individual grid cells were associated to the watershed they belonged to and assigned the watershed's surface area as value. If a grid cell was not located in any watershed, it was considered as oceanic cell. We categorised grid cells from small watersheds $\left(<10 \mathrm{~km}^{2}\right)$ to continental rivers $\left(>1,000,000 \mathrm{~km}^{2}\right)$ by orders of magnitude of surface area $(7$ categories in total). The main motivation behind this analysis was to identify the fraction of global plastic waste generated in coastal areas against the fraction generated inland that may reach the marine environment via rivers. The surface area of watersheds naturally decreases while approaching the coast from land. Some smaller watershed may be found in land generally in arid regions such as desert or mountains. As the waste generation in these areas is very small since they are generally unpopulated, we neglected the contribution of these regions from inland inputs.

\section{Results}

Global plastic waste generation. Combining country-level data on self-reported per capita municipal solid waste (Waste Atlas, 2016) generation with high resolution (30 arc seconds) distributions of global population (Landscan, 2014) and GDP (UNEP/ DEWA/GRID-Geneva, 2012), we estimated plastic waste generation at local level. The estimate reflects differences in consumption within a country, differentiating between consumption rates in urban and rural areas. Based on self-reported levels of inadequate disposal, we estimated between 60 and 99 (mid-point: 80) million metric tonnes $(\mathrm{Mt})$ of municipal plastic waste were inadequately disposed globally into the environment during 2015 (Fig. 2). The quantity represents about $47 \%$ of the global annual municipal plastic waste generation (mid-point estimate of $181 \mathrm{Mt}$ for $n=188$ countries).

Hosting $60 \%$ of the global population (United Nations, 2015), the Asian continent was in 2015 the leading generating region of plastic waste with $82 \mathrm{Mt}$, followed by Europe $(31 \mathrm{Mt})$ and Northern America $(29 \mathrm{Mt})$. Latin America (including the Caribbean) and Africa each produced $19 \mathrm{Mt}$ of plastic waste while Oceania generated about $0.9 \mathrm{Mt}$. However, the proportion of produced waste that was inadequately disposed varied across regions (Waste Atlas, 2016). We derived quantities of MPW from reported waste management data per countries and per capita GDP. As a significant level of uncertainty is associated with the data on municipal waste management, we introduced lower and upper ranges along with our midpoint estimate and thereafter reported the ranges in brackets. With an average of $63 \%$ of inadequately disposed waste for 2015, Asia released $52(42-58)$ Mt of plastic waste into the environment, representing $65 \%$ of the global MPW generation. Africa, however, had the highest rate of unsound waste disposal with an average of $88.5 \%$ resulting in a total of 17 (10-20) Mt of unsoundly disposed plastic waste despite the low levels of resin production. Latin America and the Caribbean were the third generating region with $7.9(6.7-8.3) \mathrm{Mt}$, followed by Europe with 3.3 (1.3-9.1) Mt, Northern America with $0.3(0.03-3.0) \mathrm{Mt}$, and Oceania with $0.14(0.05-0.32) \mathrm{Mt}$. Interestingly, except with Asia, the regions with unsoundly disposed plastics, do not correspond to production volumes of plastics in these regions; the Middle East and Africa account for only $7 \%$ of resin production while US and Europe each account for $20 \%$ of global plastics production. The unfair practice of importing waste, especially e-waste, from developed nations, is to a large part responsible for this problem in Africa for example (Schmidt, 2006).

We ranked contributors by mid-point estimate of MPW generation at regional and national scale (Table 2). The generation of waste from the Asian continent was distributed between Southern, Eastern and South-East Asia with respectively 18.4, 17.4 and $11.7 \mathrm{Mt} \mathrm{y}^{-1}$ of annual MPW generation. Inputs from China with $17.2 \mathrm{Mty}^{-1}$, and India with $14.4 \mathrm{Mt} \mathrm{y}^{-1}$ dominated the waste generation figures for Asia. These two countries provide over a third of the global MPW generation. The Philippines were the third generating country with $4.52 \mathrm{Mt}^{-1}$ but Manila, its capital, was predicted as the largest urban centre for the generation of MPW with at least $0.81 \mathrm{Mt} \mathrm{y}^{-1}$ for the 
Table 2 Top regional and national generators of MPW in Mt $y^{-1}$ for 2015

\begin{tabular}{llll} 
Top 10 regions & Mt y $^{-\mathbf{1}}$ & Top $\mathbf{1 0}$ countries & $\mathbf{M t ~ y}^{\mathbf{- 1}}$ \\
\hline Southern Asia & $18.4(15.1-20.2)$ & China & $17.2(14.7-18.2)$ \\
Eastern Asia & $17.4(14.7-18.9)$ & India & $14.4(12.4-15.1)$ \\
South-East Asia & $11.7(9.48-12.8)$ & Philippines & $4.52(3.91-4.72)$ \\
Eastern Africa & $5.89(2.93-7.10)$ & Brazil & $3.68(3.19-3.84)$ \\
South America & $5.81(5.05-6.05)$ & Turkey & $2.15(1.86-2.24)$ \\
Western Africa & $4.47(2.69-5.22)$ & Nigeria & $1.90(1.43-2.05)$ \\
Western Asia & $3.31(2.48-4.45)$ & Tanzania & $1.77(0.80-2.24)$ \\
Northern Africa & $3.40(2.67-3.83)$ & Thailand & $1.77(1.52-1.86)$ \\
Eastern Europe & $2.66(0.95-5.34)$ & Indonesia & $1.63(1.37-1.73)$ \\
Middle Africa & $2.39(1.34-2.86)$ & Egypt & $1.60(1.28-1.76)$
\end{tabular}

The regions and countries are ranked by midpoint values, the confidence interval is provided inside the parenthesis. See Supplementary Table 1 for a definition of regions per countries.

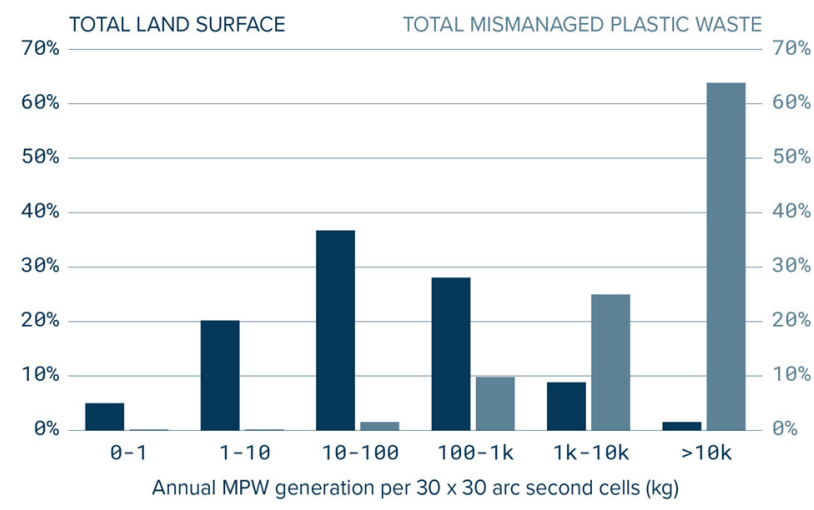

Fig. 3 Distribution of annual MPW generation over total land surface area. Modelled cells were classified by rate of MPW generation (0-1, 1-10, ..., $>10 \mathrm{~kg} \mathrm{y}^{-1}$ ). Total land surface area (blue, expressed in $\%$ of total modelled surface) and total MPW generation (grey, expressed in \% of total generation) are represented for each cell category

agglomeration, the same annual amount as produced by countries like Sudan or Algeria. Five of the top 10 countries for mismanaged plastic waste identified by this model include only 5 of the top ten countries identified by Jambeck et al. (2015) for 2010. Except for Tanzania, all ten were identified in the top 20 countries in this previous work. However, at least a part of this discrepancy might be due to differences in methodology adopted in previous and present studies. The finer granularity of the present model allows us to predict local scale accumulation. Solid waste is mostly an urban phenomenon (Hoornweg et al., 2013) and our model confirms this by predicting substantial accumulation around cities and near axes of transportation with $89 \%$ of global MPW produced over $10 \%$ of the total modelled landmass, and $64 \%$ over less than $1.5 \%$ (Fig. 3). High resolution renderings of MPW generation on land are presented in Supplementary Figure 4. We ranked global urban centres by MPW generation. Manila, the largest contributor predicted by our model, was followed by Cairo and Kolkata with 0.53 and $0.48 \mathrm{Mt} \mathrm{y}^{-1}$. Sao Paolo in Brazil was ranked fourth with $0.47 \mathrm{Mt} \mathrm{y}^{-1}$. The rest of the top 10 cities were in Asia with Bangkok $\left(0.45 \mathrm{Mt} \mathrm{y}^{-1}\right)$, New Delhi $\left(0.41 \mathrm{Mt} \mathrm{y}^{-1}\right)$, Shanghai $\left(0.5 \mathrm{Mt} \mathrm{y}^{-1}\right)$, Kuala Lumpur $\left(0.29 \mathrm{Mt}^{-1}\right)$, Beijing $\left(0.28 \mathrm{Mt} \mathrm{y}^{-1}\right)$ and Guangzhou $\left(0.27 \mathrm{Mt}^{-1}\right)$.

Future scenarios. We predicted future plastic waste generation by considering population (United Nations, 2015) and GDP (IMF, 2016; OECD, 2014) growth rates per country. By 2020, under a business-as usual-scenario for plastic consumption, our predictive model suggested the world will produce above $200 \mathrm{Mt}$ of municipal plastic waste annually and around $230 \mathrm{Mt}$ by 2025 . This is in good agreement with previous projections of solid waste generation (Hoornweg et al., 2013) with daily estimates above $6 \mathrm{Mt}$ in 2025. Considering global average proportion of plastic in municipal solid waste (10.9\%, lower: $8.3 \%$, upper: $13.2 \%)$, a daily input of $6 \mathrm{Mt}$ of solid waste may represent around 239 (182-290) Mt of annual generation of municipal plastic waste. Based on long term projections of population and GDP per countries, we estimated the global municipal plastic waste generation could reach $300 \mathrm{Mt}$ annually by 2040 and $380 \mathrm{Mt}$ by 2060 . This increase is also in good agreement with municipal solid waste generation projections which are not expected to peak within this century (Hoornweg et al., 2013). To predict the total mismanaged fraction (MPW) of future plastic production, we initially considered two scenarios. In scenario A, we assumed the case of business-as-usual where the level of waste management remains at the current status in different countries worldwide. In scenario B, we assumed waste management efforts will improve with increased investment in infrastructure as the economies in individual countries grow in the future.

Following a growing demand of plastic by end-users, the MPW generation in scenario A would nearly triple from the present value of $80(60-99) \mathrm{Mt} \mathrm{y}^{-1}$ to $213(155-265) \mathrm{Mt} \mathrm{y}^{-1}$ by 2060. Midpoint plastic demand by end-users in Asia was projected to steadily increase from $99 \mathrm{Mt} \mathrm{y}^{-1}$ in 2020 to $151 \mathrm{Mt} \mathrm{y}^{-1}$ in 2040 and $193 \mathrm{Mt}$ in 2060. If no efforts are made in waste management, generation of MPW in Asia could double from $52(42-58) \mathrm{Mt} \mathrm{y}^{-1}$ in 2020 to 129 (104-150) $\mathrm{Mt}^{-1}$ in 2060. India would become the largest MPW generating country by 2035 and would reach 46.3 (38.6-52.0) Mt $\mathrm{y}^{-1}$ by 2060 , followed by China with 33.3 (28.1-36.8) $\mathrm{Mt} \mathrm{y}^{-1}$ and the Philippines with 11.6 (10.1-12.4) Mt $\mathrm{y}^{-1}$. According to scenario A, cities like Manila, Cairo, Kolkata or New Delhi would reach the $1 \mathrm{Mty}^{-1}$ mark for annual MPW generation before 2060. However, if we assume a gradual improvement of waste management infrastructures with scenario $\mathrm{B}$, we estimated that global MPW generation could peak before 2020 and decrease to $50(22-94) \mathrm{Mt} \mathrm{y}^{-1}$ by 2060 . In this case, the decrease of global MPW generation would mainly be driven by the rapid economic development in Asia. We found that the continent could reduce MPW generation below $30 \mathrm{Mt} \mathrm{y}^{-1}$ by 2040 and below $10 \mathrm{Mty}^{-1}$ by 2060 . This scenario would mean reducing mismanaged waste below $10 \%$ of total generated waste by around 2030 for current major contributors such as China, Thailand, Indonesia or Turkey, and around 2060 for countries like India, the Philippines, or Vietnam. Our model shows how the main contribution to global MPW production would then shift from Asia to Africa. Our projections suggested that African demand by consumers for plastic will increase exponentially in the future decades from $23 \mathrm{Mt} \mathrm{y}^{-1}$ of municipal plastic waste in 

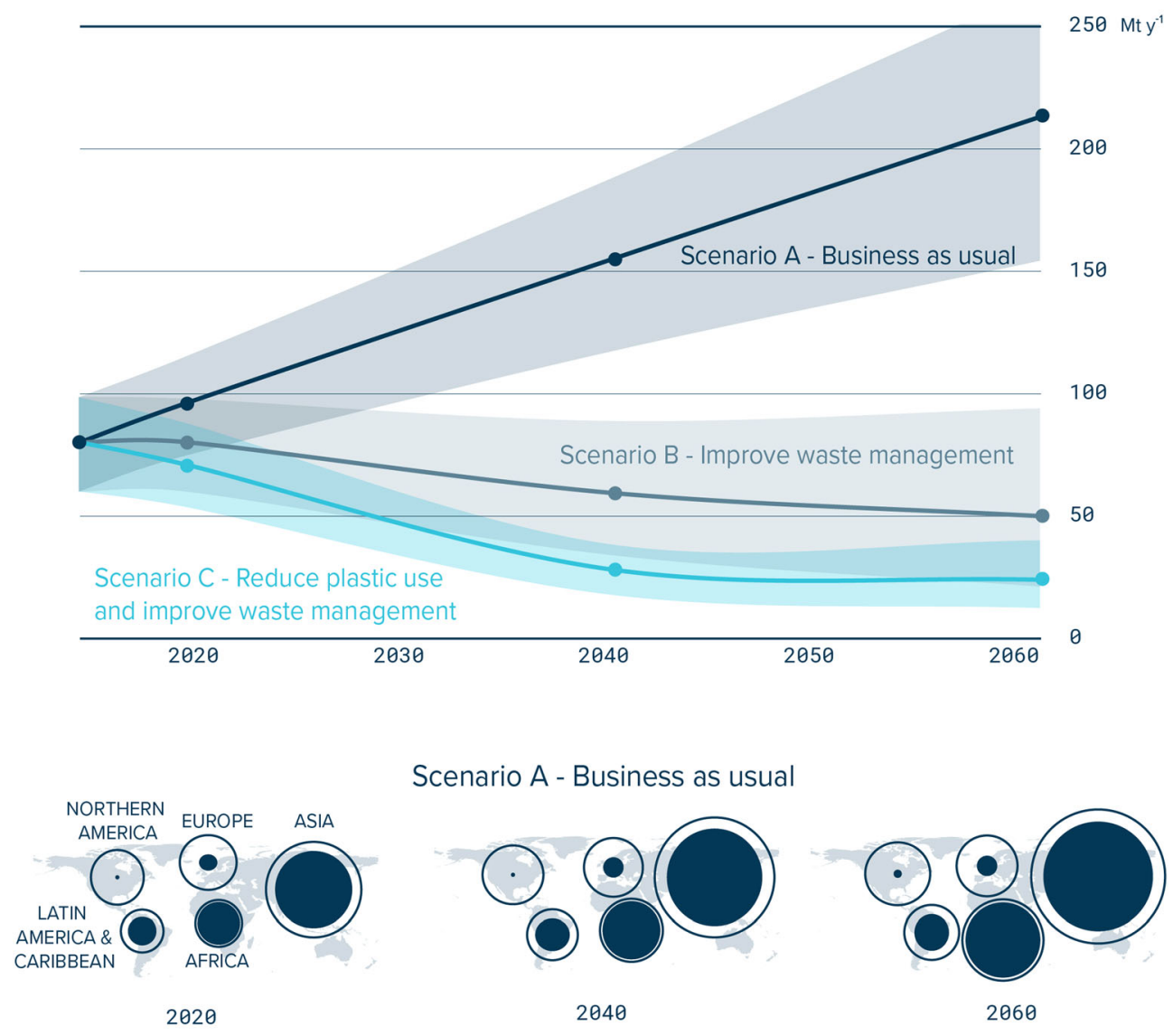

Scenario B - Improve waste management

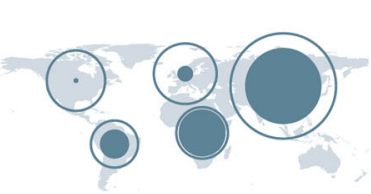

2020

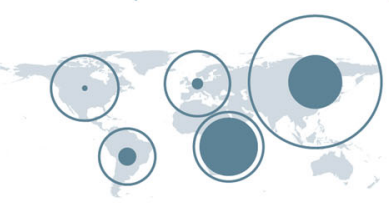

2040

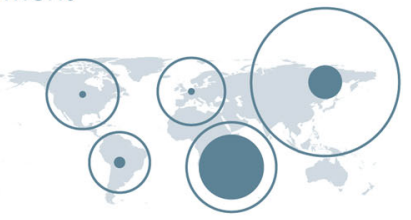

2060

Scenario C - Reduce plastic use and improve waste management

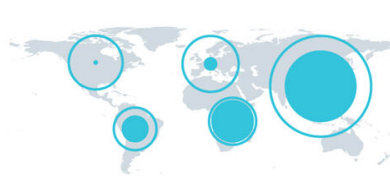

2020

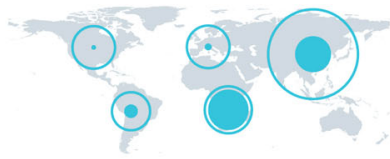

2040

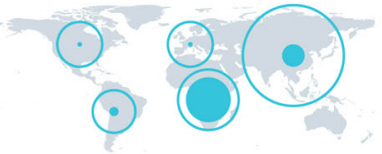

2060

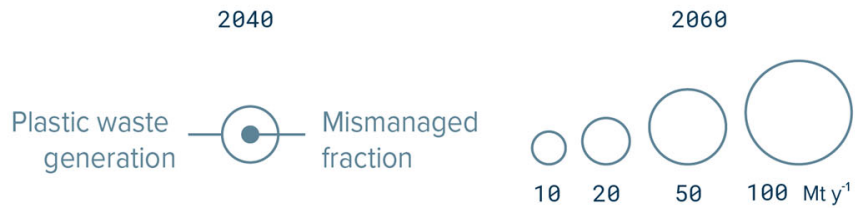

Fig. 4 Future projections of global mismanaged plastic waste (MPW) generation and distribution per continent under three scenarios. Scenario A corresponds to a business-as-usual case where the level of waste management corresponds to data for 2015 and consumer demand for plastic increases with economy. Scenario B considers that waste management infrastructures improve as per capita GDP grows. Scenario C reflects a reduction in plastic demand per capita with fraction of plastic in municipal solid waste capped at $10 \%$ by 2020 and $5 \%$ by 2040 , waste management gradually improves as in scenario B. (Top, graph) The global midpoint estimates for MPW generation are represented with thick lines while the shaded areas represent our confidence interval. (Bottom, maps) Continental distribution of MPW generation in 2020, 2040 and 2060 under the three investigated scenarios 

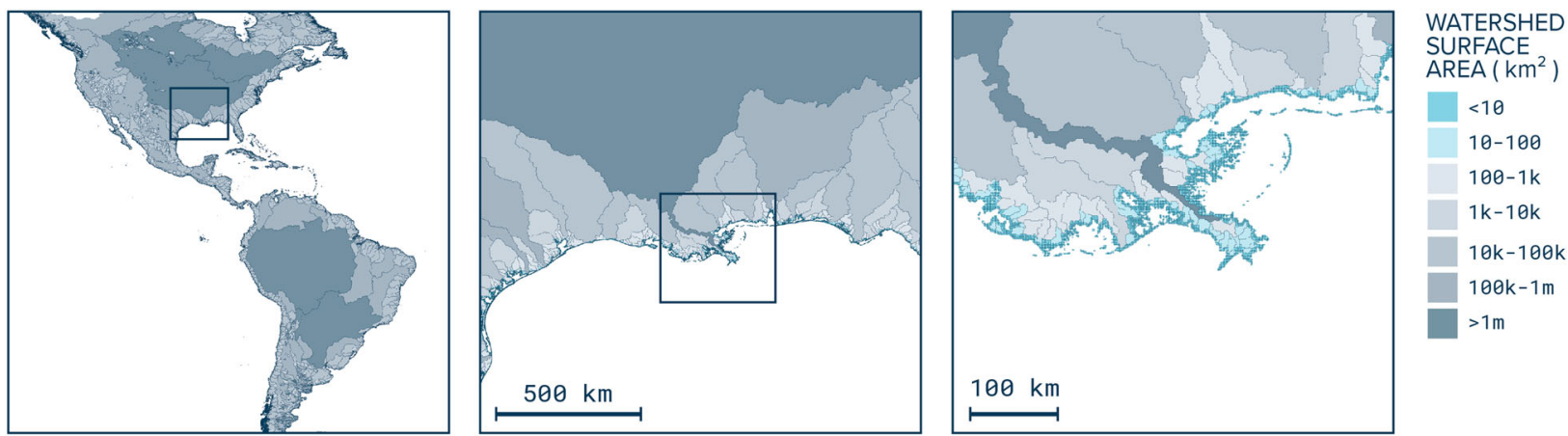

MISMANAGED MUNICIPAL PLASTIC WASTE BY WATERSHED SIZE CATEGORIES (2015)

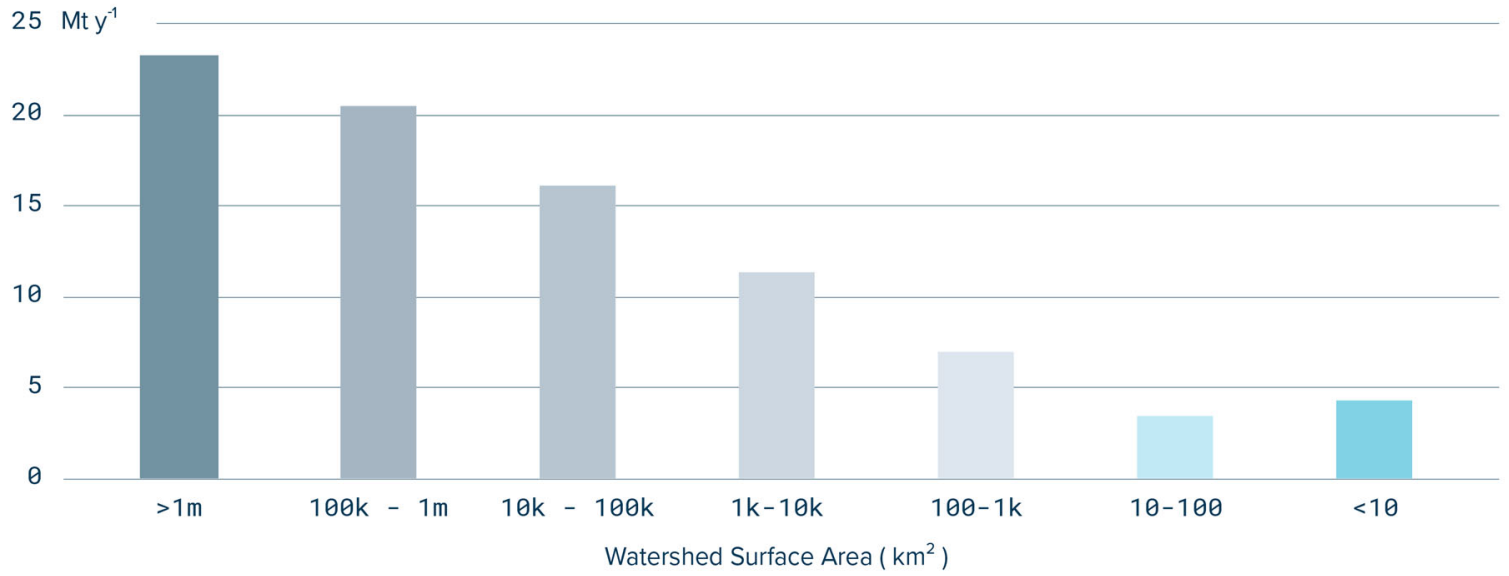

Continental rivers Rivers

Streams

Coastal watersheds

Fig. 5 Distribution of global mismanaged plastic waste (MPW) generation in 2015 by watershed size categories. The surface area of a watershed is a good indicator to differentiate coastal watersheds from large rivers. An example (top) is shown for the Mississippi river mouth with watersheds of different size categories. The global generation of mismanaged waste was binned into surface area categories (bottom) from coastal watersheds $\left(<10 \mathrm{~km}^{2}\right)$ to continental rivers $\left(>1,000,000 \mathrm{~km}^{2}\right)$

2010 to $72 \mathrm{Mt}^{-1}$ in 2060 . The demand for plastic by end-users in Africa was projected higher than in Northern America or Europe by 2035 . Under this scenario, by 2060,8 out of the 10 generating country will be an African country with Nigeria (3.08-6.46 $\left.\mathrm{Mt}^{-1}\right), \quad$ Congo (2.22-6.33 Mt y $\left.\mathrm{M}^{-1}\right)$, Tanzania (1.16-6.42 $\left.\mathrm{Mt}^{-1}\right)$, Ethiopia (1.01-4.10 $\left.\mathrm{Mt} \mathrm{y}^{-1}\right)$, Niger $\left(0.88-2.69 \mathrm{Mt}^{-1}\right)$, Sudan $\left(0.38-2.00 \mathrm{Mt} \mathrm{y}^{-1}\right)$, Mozambique $\left(0.82-1.64 \mathrm{Mt}^{-1}\right)$ and Mali $\left(0.47-1.78 \mathrm{Mt} \mathrm{y}^{-1}\right)$.

Finally, we investigated an alternative option where demand of plastic per capita would substantially decrease in the future. We introduced a third scenario $\mathrm{C}$, where waste management efforts improve as the economy of a country grows like in scenario $\mathrm{B}$, but also where plastic use by households is reduced to $10 \%$ of municipal solid waste by 2020 and to $5 \%$ by 2040 , reflecting willingness from country to curb waste generation and ban single-use plastics. This objective is reachable as some developed economies already demonstrates such low rate. Notably Denmark, first country to introduce a tax on plastic bags in 1993 for example, now reporting $1 \%$ of municipal waste composed of plastic (Waste Atlas, 2016). We found no significant relation between fraction of plastic in solid waste and per capita GDP. Some strong economies for example reported large fractions such as The Netherlands, largest reported figure for a developed economy with $19 \%$ of plastic in municipal solid waste. Under a scenario where countries would align to reduce fraction of plastic in municipal waste to below $5 \%$, the global plastic waste generation would drop to around $140 \mathrm{Mt}$ per year by 2040 but increase again to 2015 levels with nearly $180 \mathrm{Mt}$ per year in 2060 as global population grows. Combined with a gradual investment in waste management infrastructure however, the global MPW generation could be reduced to a third of current value with annual average generation below $25 \mathrm{Mt} \mathrm{y}^{-1}$ before 2060 including $74 \%$ generated in Africa and $21 \%$ in Asia. Long term projections for global MPW generation for scenario A, B and C are presented in Fig. 4 as well as distributions per continent. A full breakdown of results per sub-region with confidence interval for 2020, 2040 and 2060 is given for scenario A, B and C in Supplementary Tables 2, 3 and 4 .

Sources to ocean. The rapid accumulation of MPW on land can result in the contamination of waterways and eventually the marine environment. Through runoff, winds, and gravity, plastic debris slowly makes its way downhill and enters the sea from coastal environments (Jambeck et al., 2015) and through rivers (Lebreton et al., 2017). A first global estimate of plastic inputs from land to the sea for 2010 (Jambeck et al., 2015) proposed to consider municipal plastic waste generation for population living within $50 \mathrm{~km}$ from the coastline and assumed 25\% (15-40\%) of plastic waste from this population enters the ocean. Under this condition, we predicted a total of $20.5 \mathrm{Mt}$ of MPW for coastal population in 2010. Following the study, this quantity may be converted to an annual global input into sea of 5.1 (3.1-8.2) Mt. The fraction of plastic waste entering the ocean may vary between locations, however. The magnitude and timing of plastic waste displacement on land is poorly known (Horton et al., 2017) and may be a function of topography, land use, climate, vegetation 
and, particle shape and size (e.g., microplastics may be more easily transported than larger, more complexly shaped debris).

Considering populations living within a fixed distance from the coastline may not always be representative of land-based sources to the ocean as plastic waste generated inland can be transported by rivers. Predicted accumulation of plastic waste on land can be distributed into watersheds (Lebreton et al., 2017). Here, we categorised watersheds by surface area considering that small watersheds are located directly at the coastline while larger watersheds may expand in land and form streams and rivers (Fig. $5)$. We grouped watersheds by orders of magnitude in surface area from coastal watersheds $\left(<10 \mathrm{~km}^{2}\right)$ to continental rivers $\left(>1,000,000 \mathrm{~km}^{2}\right)$. From our global distribution of mismanaged plastic waste for 2015, we estimated that $5 \%$ of waste was discarded directly near the coastline (watershed surface area $<$ $10 \mathrm{~km}^{2}$ ) and $4 \%$ at proximity to the coastline $\left(10\right.$ to $\left.100 \mathrm{~km}^{2}\right)$. This result shows that the majority (91\%) of MPW was generated inside larger watersheds $\left(>100 \mathrm{~km}^{2}\right)$ and suggests that rivers may be a major vector of transport of plastic waste from land into the ocean. Over a quarter of the global waste was discarded into the watersheds of only 14 continental rivers $\left(>1,000,000 \mathrm{~km}^{2}\right.$, namely the Mississippi, the Nelson, the St Lawrence, the Amazon, the Paraná, the Congo, the Niger, the Nile, the Zambezi, the Volga, the Lena, the Amur, the Yangtze and the Ganges rivers).

\section{Discussion}

Here we present for the first time, spatial distributions of mismanaged municipal plastic waste generation at an order of $1 \mathrm{~km}$ resolution, worldwide from now to 2060 . As synthetized in this study, these results can be interpreted at global, regional, national and local scale. This information at this level of resolution for GDP and population density, even with the limitation of lowresolution waste generation data, is important as it can help policy makers target priority areas for mitigation and development of waste management infrastructures. Furthermore, projected into the future, this dataset can assist countries, regions and municipalities in fixing objectives to reduce generation of plastic waste and limit releases into the environment. China and India currently contribute to above a third of the global MPW generation, with GDP growth rate projected above $4 \%$ until mid2020 s and early $2040 \mathrm{~s}$ respectively (OECD, 2014). Under a business-as-usual scenario, it is fair to expect that consumer demand for plastic will dramatically increase in these countries. According to the World Bank (Hoornweg and Bhada-Tata, 2012), 70 and $85 \%$ of municipal waste is currently mismanaged in China and India, respectively. It is crucial for cities and municipalities in these countries to invest in waste management and prepare for the surge in consumer plastic demand predicted for the future decades and the associated waste management needs. A scenario where China and India reduce the fraction of mismanaged waste to $50 \%$ by respectively 2020 and 2030 , and to the current western standard by 2035 and 2050, along with other countries in similar economic transition, shows that we could reach peak generation of MPW at global scale in the next decade. Our results highlight the urgency of the situation and the necessity of an international law-abiding agreement between countries on the management of plastic waste as we could be generating twice the current amount of MPW per year, globally, by mid-century if the situation remains unchanged. These should focus on anti-dumping of waste in developing countries, developing better recycling architectures and standardising technologies to prevent escape of microplastics from land-based sources into the ocean.

However, our results also suggest that gradual increase in waste management infrastructure may not be enough for some parts of the world. Our projections show some countries, particularly in
Africa, that may not reach this transition before 2060. The consumer demand for plastic in Africa was projected to grow by $375 \%$ from the current demand by 2060, the highest growth for a continent, the global average being $210 \%$. This exponential increase in demand for plastics by the end-user is fuelled by GDP growth but also by a substantial increase of population. Africa's demographic is expected to reach 2.9 billion by 2060 (United Nations, 2015) representing a population growth of $245 \%$ from 2015, much higher than any other continents (global average: $138 \%)$. As a result, despite GDP growth, the per capita GDP remains sufficiently low for our model to consider a large portion of produced waste to be likely mismanaged. These assumptions may have to be further questioned however it is an indication that resolving the global issue of plastic contamination in the environment may require cooperation between cities and countries as well as the promotion of further international aid for waste management in the future. But more importantly, it shows that GDP-fuelled demand for plastics by end-users is not sustainable at global scale and support the necessity to introduce quotas in plastic use. In a scenario where the plastic fraction in municipal solid waste is capped to $10 \%$ by 2020 and to $5 \%$ by 2040 , the release of plastic into the environment could be efficiently reduced to a third of the current level, assuming significant improvement are also made in terms of waste management to compensate for population growth. Prohibition of single-use plastics is currently being proposed in policies of cities, countries and regions around the world. To efficiently mitigate the release of plastic waste into the environment in the future, our results emphasise two aspects with (1) the improvement of waste management infrastructure as well as our capacity of recycling waste and (2) the introduction of a limit on fraction of plastic in solid waste per capita reflecting reduction in demand for single-use plastics.

The analysis of our results may not only be constrained to political boundaries as in this study, we show how considering physical boundaries may help in understanding the generation of plastic waste in watersheds and indirectly sources of plastic to the ocean (Lebreton et al., 2017; Schmidt et al., 2017). Our data is made available to assist hydrologist and geologist in quantifying sources of plastic litter in rivers and soils (Gonzalez et al., 2016; van Emmerik et al., 2018). This is an important aspect as we also show that most of the produced MPW each year is located inside larger watersheds characterised by a river and several confluents. Understanding the geography of waste generation can help targeting rivers for mitigation and eventually reduce the source of plastic waste to the ocean. The transport of plastic litter on land is poorly understood and additional site-specific work may be required to quantify the portion of litter that is stored in soils and the portion that enters waterways, and subsequently the ocean. Other physical boundaries of interest are the average ultraviolet radiation levels received by unit of surface area or the average ground air temperature as these environmental parameters may dictate degradation processes for plastic waste on land and therefore microplastics generation rate. Well outside the scope of this study, we noticed however that the current plastic demand by end-users is dominantly distributed in regions with a temperate climate, but our projections shows that this demand will shift towards lower latitude, in much warmer climate, within the course of this century with predicted major consumers in Southern Asia, South-Eastern Asia or in Africa. The foregoing discussion was based on MPW in general. However, recent research specifically points to ecological impacts of meso-plastics, micro-plastics and nano-plastics in the ocean environment (Avio et al., 2017). These smaller fragments are generated by weathering degradation of plastic debris in the outdoor environment, especially beaches, followed by mechanical action of wind and waves fragmenting the degraded plastics (Andrady, 2017). A combination of solar UV 
radiation and high sample temperatures are well known to control the rates of degradation and therefore the fragmentation of MPW into micro-particles (Abdelhafidia et al., 2015). Fragmentation of common plastics into micro- and nano-sized particles has been demonstrated in laboratory (Wohlleben and Neubauer, 2016; Kalogerakis et al., 2017). It is difficult to accurately quantify the rates of potential micro-plastics generation at a given location as the fraction of MPW exposed to solar radiation cannot be easily assessed. But those locations of high solar irradiance and high ambient temperatures might be qualitatively expected to promote faster weathering and fragmentation of exposed plastics waste. Considering the already developed hotspots, those in African continent will experience both high downward solar UV flux as well as high ambient temperatures followed by those in India and East Asia. The significance of these hotspots is therefore magnified because of the increased propensity to generate micro-plastics at a faster rate. Accordingly, they demand more stringent efforts at plastic waste management to avoid the load of micro- and nanoplastics they may generate via weathering.

It is important to note that some uncertainties are associated to our estimates. To reflect these, we introduced lower and upper ranges along our mid-point projections. The calculations of these confidence intervals include the uncertainties related to per capita municipal solid waste generation, proportion of plastic in waste and proportion of waste that is mismanaged. This data was reported at national level. However, values may vary inside countries. As local information is unavailable, we proposed a model to consider sub-national variations of plastic consumption. This approach naturally yields uncertainties which are also included in the calculation of our confidence interval. The confidence interval for our projections naturally increase as we progress in the future. For example, our projections neglect subnational change of population distribution since population density was assumed to grow at the same rate as the national average. This assumption may introduce a bias in our projections. Rural exodus may further reinforce urban influences on waste production in the future. Also, our projections do not consider plastic waste exports or imports for reprocessing: in 2012, for instance, $15 \mathrm{Mt}$ was traded, mainly between Europe and China. The import of waste for recycling has recently been shut down from China however and many countries now face difficulties to handle the accumulated plastic from curb-side collection. Similarly, our model cannot account for future exceptional economic, societal or financial events. Advances in technology, consumer product design, and behaviour patterns may change the per capita GDP-consumption relationship as well as conversion rates of waste to MPW. Generally, we encourage the systematic reporting of waste management data at sub-national scale by countries to reduce some of the uncertainties introduced above. Better reporting of waste management practices could lead to the development of a national plastic waste emission, similarly to the creation of carbon emission index by climate scientists (Le Quéré et al., 2018). Such index would foster international cooperation and assist countries and municipalities in setting objectives to reduce plastic waste releases into natural environments.

\section{Data availability}

Gridded distributions of total and mismanaged municipal plastic waste generation are available on Figshare in.tif format as well as a country scale results summary spreadsheet (Lebreton and Andrady, 2018).

Received: 5 July 2018 Accepted: 13 December 2018

Published online: 29 January 2019

\section{References}

Abdelhafidia A, Babaghayoua IM, Chabiraa SF, Sebaaa M (2015) Impact of solar radiation effects on the physicochemical properties of polyethylene (PE) plastic film. Procedia Social Behav Sci 195:2922-2929

Andrady AL (2011) Microplastics in the marine environment. Mar Pollut Bull 62 (8):1596-1605

Andrady AL (2017) The plastic in microplastics: a review. Mar Pollut Bull 119 (1):12-22

Andrady AL, Neal MA (2009) Applications and societal benefits of plastics. Philos Trans R Soc B 364(1526):1977-1984

Au SY, Lee CM, Weinstein JE, van den Hurk P, Klaine SJ (2017) Trophic transfer of microplastics in aquatic ecosystems: Identifying critical research needs. Integr Environ Assess Manag 13(3):505-509

Avio C, Gorbi S, Regoli F (2017) Plastics and microplastics in the oceans: from emerging pollutants to emerged threat. Mar Env Res 128:2-11

Barnes D, Galgani F, Thompson R, Barlaz M (2009) Accumulation and fragmentation of plastic debris in global environments. Philos Trans R Soc B: Biol Sci 364(1526):1985-1998

British Plastics Federation (2008) Oil consumption. British Plastics Federation. http://www.bpf.co.uk/press/Oil_Consumption. Accessed 20 Apr 2018

Chen Q, Reisser J, Cunsolo S, Kwadijk C, Kotterman M, Proietti M, Slat B, Ferrari FF, Schwarz A, Levivier A, Yin D, Hollert H, Koelmans AA (2017) Pollutants in plastics within the North Pacific subtropical gyre. Environ Sci Technol 52 (2):446-456

Secretariat of the Convention on Biological Diversity and the Scientific and Technical Advisory Panel-GEF (2012) Impacts of marine debris on biodiversity: current status and potential solutions. Montreal, Technical Series No. 67. Secretariat of the Convention on Biological Diversity.

E.P.A. (2016) Advancing sustainable materials management: 2014 fact sheet. Assessing trends in material generation, recycling, composting, combustion with energy recovery and landfilling in the United States. United States Environmental Protection Agency, Office of Land and Emergency Management, Washington DC

Geyer R, Jambeck J, Law KL (2017) Production, use, and fate of all plastics ever made. Sci Adv 3(7):e1700782

Gonzalez FD, Hanke G, Tweehuysen G, Bellert B, Holzhauer M, Palatinus A, Hohenblum P, Oosterbaan L (2016) Riverine litter monitoring-options and recommendations. MSFD GES TG Marine Litter Thematic Report, JRC Technical Report, EUR 28307. https://doi.org/10.2788/461233. Accessed 10 Oct 2018

Hammond GP and Jones CI (2008) Embodied energy and carbon in construction materials. Proc Inst Civil Eng Energ 161(2): 87-98

Heskett M et al. (2012) Measurement of persistent organic pollutants (POPs) in plastic resin pellets from remote islands: toward establishment of background concentrations for International Pellet Watch. Mar Pollut Bull 64(2):445-448

Hoornweg D and Bhada-Tata P (2012) What a waste: a global review of solid waste management. World Bank. http://hdl.handle.net/10986/17388. Accessed 28 Feb 2016

Hoornweg D, Bhada-Tata P, Kennedy C (2013) Environment: waste production must peak this century. Nature 502:615-616

Horton AA, Walton A, Spurgeon DJ, Lahive E, Svendsen C (2017) Microplastics in freshwater and terrestrial environments: Evaluating the current understanding to identify the knowledge gaps and future research priorities Sci Total Environ 586:127-141

IMF (2016) World Economic Outlook Database. International Monetary Fund https://www.imf.org/external/pubs/ft/weo/2016/02/weodata/index.aspx. Accessed 28 Nov 2016

Ivar do Sul JA, Costa MF (2014) The present and future of microplastic pollution in the marine environment. Environ Pollut 185:352-364

Jambeck JR, Geyer R, Wilcox C, Siegler TR, Perryman M, Andrady A, Narayan R, Law KL (2015) Plastic waste inputs from land into the ocean. Science 347 (6223):768-771

Kalogerakis N, Karkanorachaki K, Kalogerakis G, Triantafyllidi EI, Gotsis AD, Partsinevelos P, Fava FH (2017) Microplastics generation: onset of fragmentation of polyethylene films in marine environment mesocosms. Front Mar Sci 4:84

Landscan (2014) Global population database. Oak Ridge National Laboratory. http://web.ornl.gov/sci/landscan. Accessed 26 June 2017

Le Quéré C, Andrew RM, Friedlingstein P, Sitch S, Pongratz J, Manning AC, Korsbakken JI, Peters GP, Canadell JG, Jackson RB, Boden TA, Tans PP, Andrews OD, Arora VK, Bakker DCE, Barbero L, Becker M, Betts RA, Bopp L, Chevallier F, Chini LP, Ciais P, Cosca CE, Cross J, Currie K, Gasser T, Harris I, Hauck J, Haverd V, Houghton RA, Hunt CW, Hurtt G, Ilyina T, Jain AK, Kato E, Kautz M, Keeling RF, Klein Goldewijk K, Körtzinger A, Landschützer P, Lefèvre N, Lenton A, Lienert S, Lima I, Lombardozzi D, Metzl N, Millero F, Monteiro PMS, Munro DR, Nabel JEMS, Nakaoka S-I, Nojiri Y, Padin XA, Peregon A, Pfeil B, Pierrot D, Poulter B, Rehder G, Reimer J, Rödenbeck C, Schwinger J, Séférian R, Skjelvan I, Stocker BD, Tian H, 
Tilbrook B, Tubiello FN, van der Laan-Luijkx IT, van der Werf GR, van Heuven S, Viovy N, Vuichard N, Walker AP, Watson AJ, Wiltshire AJ, Zaehle S, Zhu D (2018) Global Carbon Budget 2017. Earth Syst Sci Data 10:405-448

Lebreton L and Andrady A (2018) Supplementary data for 'Future scenarios of global plastic waste generation and disposal'. figshare. https://doi.org/10.6084/ m9.figshare.5900335

Lebreton L, van der Zwet J, Damsteeg JW, Slat B, Andrady A, Reisser J (2017) River plastic emissions to the world's oceans. Nat Commun 8:15611

Lehner B, Verdin K, Jarvis A (2008) New global hydrography derived from spaceborne elevation data. Eos, Trans, AGU 89(10):93-94

Lenzing Group (2016) Factsheet. Lenzing Group. http://www.lenzing.com/en/ investors/factsheet.html. Accessed 12 Dec 2017

Mason SA, Garneau D, Sutton R, Chu Y, Ehmann K, Barnes J, Fink P, Papazissimos D, Rogers DL (2016) Microplastic pollution is widely detected in US municipal wastewater treatment plant effluent. Environ Pollut 218:1045-1054

OECD (2014) Economic outlook no 95. Long-term baseline projections. Organisation for Economic Co-operation and Development. http://stats.oecd.org/ Index.aspx?DataSetCode=EO95_LTB. Accessed 28 Nov 2016

Plastics Europe (2014) Plastics-The facts. Plastic Europe. https://www. plasticseurope.org/en/resources/publications/95-plastics-facts-2014. Accessed 12 Dec 2017

Plastics Europe (2017) Plastics-The facts. Plastic Europe. https://www. plasticseurope.org/en/resources/publications/274-plastics-facts-2017. Accessed 20 Apr 2018

Rillig MC (2012) Microplastic in terrestrial ecosystems and the soil. Environ Sci Technol 46(12):6453-6454

Santillo D, Miller K, Johnston P (2017) Microplastics as contaminants in commercially important seafood species. Integr Environ Assess Manag 13:516-521

Schmidt C, Krauth T, Wagner S (2017) Export of plastic debris by rivers into the sea. Environ Sci Technol 51(21):12246-12253

Schmidt CW (2006) Unfair Trade e-Waste in Africa. Environ Health Perspect 114 (4):232-235

UNEP/DEWA/GRID-Geneva (2012) Gross domestic product 2010. United Nations Environment Program. https://preview.grid.unep.ch/. Accessed 22 Dec 2016

United Nations (2015) Probabilistic population projections based on the world population prospects: the 2015 revision. United Nations Department of Economic and Social Affairs. https://esa.un.org/unpd/wpp/publications/Files/ WPP2015_Volume-I_Comprehensive-Tables.pdf. Accessed 28 Nov 2016

Van Cauwenberghe L, Janssen CR (2014) Microplastics in bivalves cultured for human consumption. Environ Polut 193:65-70

van Emmerik T, Kieu-Le TC, Loozen M, van Oeveren K, Strady E, Bui XT, Egger M, Gaspéri J, Lebreton L, Nguyen PD, Schwarz A, Slat B, Tassin B (2018) A methodology to characterize riverine macroplastic emission into the ocean. Front Mar Sci 5:372

Waste Atlas (2016) D-waste. Waste Atlas. http://www.atlas.d-waste.com/. Accessed 4 Aug 2016
Wohlleben W, Neubauer N (2016) Quantitative rates of release from weathered nanocomposites are determined across 5 orders of magnitude by the matrix, modulated by the embedded nanomaterial. NanoImpact 1:39-45

World Economic Forum (2016) The new plastics economy. Rethinking the future of plastics. World Economic Forum, Geneva, Switzerland

\section{Acknowledgements}

This study was made possible thanks to the open-access distribution of several global dataset including the Waste Atlas, the LandScan 2014 High Resolution Global Population Data, the GDP distribution by UNEP/DEWA/GRID-Geneva and the HydroSHEDS by USGS/WWF. We would like to thank the donors of The Ocean Cleanup Foundation who helped funding this study, as well as Dr Tim van Emmerik for reviewing this manuscript. The authors would also like to thank the participants of GESAMP Working Group 40 on Sources, Fate and Effects of Microplastics in the Marine Environment, for the valuable exchanges in the early stage of this study.

\section{Additional information}

Supplementary information: The online version of this article (https://doi.org/10.1057/ s41599-018-0212-7) contains supplementary material, which is available to authorized users.

Competing interests: The authors declare no competing interests.

Reprints and permission information is available online at http://www.nature.com/ reprints

Publisher's note: Springer Nature remains neutral with regard to jurisdictional claims in published maps and institutional affiliations.

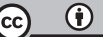

Open Access This article is licensed under a Creative Commons Attribution 4.0 International License, which permits use, sharing, adaptation, distribution and reproduction in any medium or format, as long as you give appropriate credit to the original author(s) and the source, provide a link to the Creative Commons license, and indicate if changes were made. The images or other third party material in this article are included in the article's Creative Commons license, unless indicated otherwise in a credit line to the material. If material is not included in the article's Creative Commons license and your intended use is not permitted by statutory regulation or exceeds the permitted use, you will need to obtain permission directly from the copyright holder. To view a copy of this license, visit http://creativecommons.org/ licenses/by/4.0/

(C) The Author(s) 2019 